\title{
Intoxicações natural e experimental por amitraz em eqüídeos: aspectos clínicos ${ }^{1}$
}

\author{
Marcos Dutra Duarte ${ }^{2}$, Paulo Vargas Peixoto ${ }^{3}$, Pedro Soares Bezerra Júnior ${ }^{4}$, Krishna \\ Duro de Oliveira ${ }^{5}$, Alexandre Paulino Loretti ${ }^{6}$ e Carlos Hubinger Tokarnia ${ }^{3}$
}

\begin{abstract}
Duarte M.D., Peixoto P. V., Bezerra P. S., Oliveira K. D., Loretti A. P. \& Tokarnia C.H. 2003. [Natural and experimental poisoning by amitraz in horses and donkey: Clinical aspects.] Intoxicações natural e experimental por amitraz em eqüídeos: aspectos clínicos. Pesquisa Veterinária Brasileira 23(3):105-118. Hospital Veterinário, Setor Grandes Animais, Universidade Federal Rural do Rio de Janeiro, Seropédica. RJ 23835-000, Brazil. E-mail: marcos@webcem.com.br
\end{abstract}

Poisoning by amitraz was experimentally reproduced in 17 horses and a donkey. First symptoms were observed between $15 \mathrm{~min}$. and $2 \mathrm{~h} 5 \mathrm{~min}$. after oral administration, and between $6 \mathrm{~h} 28 \mathrm{~min}$. and $8 \mathrm{~h} 38 \mathrm{~min}$. after spraying with amitraz. The course of poisoning after oral administration was 4 to 9 days, and after spraying 5 to 6 days. Death of experimental animals occurred only after oral administration. One animal was euthanized after spraying. Doses of $5.5 \mathrm{mg} / \mathrm{kg}$ (1 administration), $5.8 \mathrm{mg} / \mathrm{kg}$ ( 2 administrations) and doses which varied between 7.2 and $36.4 \mathrm{mg} / \mathrm{kg}$ ( 5 administrations) were used when amitraz was given by mouth, all causing symptoms of poisoning. When the administration of amitraz was by spraying, poisoning was reproduced with solutions of 0.1 and $0.2 \%$. Regarding the nervous system, the main signs observed were recumbency, somnolence, palpebral and auricular ptosis, difficulties in apprehension, chewing and swallowing of food, dragging of the hooves, exposure of the penis, diminished or absent cutaneous sensibility, instability, abduction of the legs, lowering of the head, incoordination, jawning, labial flacity, exposure of the tongue, crossing of the legs when walking, diminished postural response after crossing or abducting the legs, diminished/absent reflex of the upper lip, palatal, tongue, flexor and swallowing reflex, diminished auricular, palpebral and menace reflex. The ambulatory response was diminished when tested by walking in circles of small radius. Regarding the digestive system, the signs were mainly intestinal hypomotility/atony, edema of the lips, abdominal distention, frequent lying down and standing up, rolling on the ground, looking at the flancs, groaning and impaction of the large bowel. Regarding the circulatory system, the main clinical signs were tachycardia, increase of the refilling time of capillaries, congested mucosa and splitting of the cardiac sounds. Regarding the respiratory system, stridor, tachypnoea, dyspnoea, nasal discharge, bradypnoea and abdominal respiration was observed. Beside these signs, there were alterations of the general condition, as apathy and hypothermia. All natural cases occurred after spraying with amitraz. First symptoms were seen 2 to 3 days after the application of amitraz. The course was 6,7 and 17 days. One animal showed mainly the nervous signs as

${ }^{1}$ Recebido em 17 de fevereiro de 2003.

Aceito para publicação em 19 de março de 2003.

Tese de Mestrado do primeiro autor, apresentado ao Curso de Pós-Graduação em Medicina Veterinária da Universidade Federal Rural do Rio de Janeiro (UFRRJ), em 12 de fevereiro de 2003.

${ }^{2}$ Médico Veterinário, Hospital Veterinário, Setor de Grandes Animais, UFRRJ.

${ }^{3}$ Depto Nutrição Animal e Pastagem, Instituto de Zootecnia, UFRRJ, Seropédica, RJ 23835-000. E-mail: peixoto@ufrrj.br, tokarnia@ufrrj.br

\footnotetext{
${ }^{4}$ Depto Medicina Veterinária, Setor de Patologia, Universidade Federal de Lavras, Cx. Postal 37, Lavras, MG 37200-000. E-mail: bezerraj@ufla.br

${ }^{5}$ Seção de Patologia Veterinária, Curso de Medicina Veterinária, Centro Universitário, Rua Comissário José Dantas de Mello 21, Boa Vista, Vila Velha, ES 29102-770.

${ }^{6}$ Setor de Patologia Veterinária, Depto Patologia Clínica Veterinária, Faculdade de Veterinária, Universidade Federal do Rio Grande do Sul, Porto Alegre, RS 91540-000.
} 
seen in the experiments, with exception of the signs of crossing the legs when walking, yawning and exposure of the penis. Another animal had only digestive symptoms as rolling, pawing, intestinal hypomotility/atony and impaction of the large bowel. A third animal initially showed digestive symptoms characterized by pawing, rolling, intestinal atony and impaction of the large bowel, followed by laminitis; in the final stage this animal showed severe nervous signs as pressing the head against obstacles, incoordination with crossing the legs when walking and reluctance to move. Possible location of lesions in the nervous system according to the clinical signs are suggested.

INDEX TERMS: Poisoning, horses, donkey, amitraz.

RESUMO.- A administração oral e a aspersão com amitraz reproduziram experimentalmente em 17eqüinos e um asinino um quadro de intoxicação muito similar a outro que vinha ocorrendo em cavalos no Estado do Rio de Janeiro. O início dos sintomas após a administração oral variou entre $15 \mathrm{~min}$. e $2 \mathrm{~h} 05 \mathrm{~min} .$, na aplicação por aspersão variou entre $6 \mathrm{~h} 28 \mathrm{~min}$. e $8 \mathrm{~h} 38 \mathrm{~min}$. A evolução nos casos de administração oral foi de 4 a 9 dias, nos de aspersão de 5 a 6 dias. Somente morreram animais que receberam a administração oral. Um animal aspergido com o amitraz foi sacrificado. Por via oral foram usadas dosagens de $5,5 \mathrm{mg} / \mathrm{kg}$ (uma administração), $5,8 \mathrm{mg} /$ $\mathrm{kg}$ (duas administrações) e num terceiro animal, doses que variaram entre 7,2 e $36,4 \mathrm{mg} / \mathrm{kg}$ (cinco administrações). Nas aplicações por aspersão, a intoxicação foi reproduzida com soluções nas concentrações de 0,1 e $0,2 \%$. Com relação ao sistema nervoso, os principais sinais observados foram apatia, sonolência, ptoses palpebral e auricular, dificuldade de apreensão, mastigação e deglutição do alimento, arrastar das pinças dos cascos no solo, exposição do pênis, sensibilidade cutânea diminuída/ausente, instabilidade em estação, abdução dos membros, cabeça baixa, incoordenação, bocejos, flacidez labial, exposição da língua, cruzamento dos membros ao caminhar, resposta postural diminuída após cruzar e abduzir os membros, reflexos do lábio superior, palatal, lingual, de deglutição e flexor diminuídos/ausentes, reflexos auricular, palpebral e de ameaça diminuídos e resposta ambulatória diminuída ao teste de girar em círculo de pequeno raio. No que se refere ao sistema digestivo, foram evidenciados, principalmente, hipomotilidade/atonia intestinal, edema dos lábios, distensão abdominal, deitar e levantar com freqüência, rolar no solo, olhar para o flanco, gemer e impactação do intestino grosso. Observaram-se ainda taquicardia, aumento do tempo de preenchimento capilar e mucosas congestas, estridor, taquipnéia, dispnéia, secreção nasal, bradipnéia e respiração abdominal. Todos os três casos naturais ocorreram após aspersão do amitraz. Os primeiros sintomas foram observados 2 e 3 dias após o banho. A evolução foi de 6, 7 e 17 dias. Um animal manifestou a maioria dos sinais referentes ao sistema nervoso observados nos experimentos, com exceção dos sinais de cruzamento dos membros ao caminhar, bocejos, lábios flácidos e exposição do pênis. Outro animal, intoxicado espontaneamente, manifestou somente sintomas digestivos como rolar, "patear", hipomotilidade/atonia intestinal e impactação do intestino grosso. Um terceiro animal, inicialmente manifestou sintomas digestivos caracterizados por patear, rolar, atonia intes- tinal e impactação do intestino grosso, com conseqüente desenvolvimento de laminite; na fase final exibiu acentuada sintomatologia nervosa mostrando compressão da cabeça contra obstáculos, incoordenação motora com cruzamento dos membros ao caminhar e relutância em se movimentar. Baseados no quadro clínico observado, são sugeridos possíveis locais de lesão no sistema nervoso.

TERMOS DE INDEXAÇÃO: Intoxicações, equíídeos, amitraz.

\section{INTRODUÇÃO}

O amitraz é um acaricida do grupo das formamidinas utilizado no controle de ectoparasitoses em várias espécies de animais domésticos como bovinos, ovinos, cães (Gunaratnam et al. 1983) e suínos (Darvill, 1985). A partir do final da década de 1970, o uso desta droga, através de banhos de aspersão, tem sido associado a episódios de intoxicação na espécie eqüina caracterizados por sonolência, depressão, ataxia, fraqueza muscular e impactação progressiva do intestino grosso, que ocorrem dentro de 24 a 48 horas após o procedimento (Roberts \& Seawright 1979).

No Brasil existe apenas um relato de doença relacionada à utilização de amitraz na espécie eqüina, embora vários veterinários já tenham observado esta doença a campo. No Estado de São Paulo, entre 1987 e 1993, nove eqüinos que apresentaram desconforto abdominal, haviam sido submetidos a banhos de aspersão com amitraz horas antes da manifestação de síndrome cólica (Dearo \& Gandolfi 1995). Em 1992, deu entrada em nosso instituto, um equiino apresentando acentuada depressão do sistema nervoso central e ataxia, bem como diminuição da motilidade intestinal, sintomas observados após o uso de amitraz por aspersão. A partir de então, verificamos casos semelhantes, em cuja anamnese sempre havia a menção à utilização de amitraz. Paralelamente, encontramos alguns animais com a clássica sintomatologia de impactação do intestino grosso, sem sinais relativos ao sistema nervoso central (SNC), os quais também haviam sido submetidos, há pouco tempo, à aspersão com o mesmo carrapaticida.

Hoje, está bem estabelecido que o amitraz é capaz de induzir a ambos os tipos de quadros clínicos anteriormente referidos (Radostits et al. 2002). Apesar disso, muitos proprietários continuam a utilizar o acaricida, provavelmente motivados pela observação de que a maioria dos cavalos aspergidos com uma solução aquosa a $0,025 \%$ (dose terapêutica recomendada para a espécie bovina) não apresenta 
sinais de intoxicação (Seawright 1984, observações nãopublicadas).

Esse estudo tem como objetivo descrever, com mais detalhes, o quadro clínico observado nas intoxicações natural e experimental por amitraz em eqǘdeos e, sobretudo, sugerir possíveis locais de lesões no sistema nervoso responsáveis pela sintomatologia.

\section{REVISÃO DE LITERATURA}

Epidemiologia

A intoxicação por amitraz em eqüinos já foi descrita na Austrália (Roberts \& Seawright, 1979; Auer et al. 1984), Holanda (Mutsaers \& van der Veldem 1988), Brasil (Dearo \& Gandolfi 1995) e França (Hugnet \& Cadoré 1995).

Na espécie eqüina, a intoxicação por amitraz ocorre principalmente durante os banhos com o carrapaticida. (Roberts \& Seawright 1979, Auer et al. 1984, Mutsaers \& van der Velden 1988, Dearo \& Gandolfi 1995, Hugnet \& Cadoré 1995). Nos cães, além da intoxicação por meio de banhos sarnicidas (Dobozy 1982, Muller 1983, Folz et al. 1984a,b, Hovda \& McManus 1993), ocorreram também episódios de envenenamento pela ingestão de coleiras parasiticidas à base de amitraz (Grossman et al. 1993 apud Hugnet et al. 1996, Duncan 1993). Em seres humanos, geralmente a intoxicação está associada a tentativas de suicídio em adultos ou à ingestão acidental em crianças (Jones 1990, Kennel et al. 1996).

Estudos têm demonstrado que qualquer eqüino pode ser afetado através da exposição ao composto. A concentração da solução utilizada teria grande importância no desencadeamento da intoxicação. Adicionalmente, a severidade da condição clínica pode ser influenciada pelo clima e por fatores locais da pele que aumentem a taxa de absorção per cutânea (Roberts \& Seawright 1979).

\section{Aspectos toxicológicos}

O amitraz é uma substância instável em meio ácido (Harrison et al. 1973). Assim, em suspensões aquosas com pH abaixo da neutralidade, a molécula do acaricida é rapidamente hidrolisada (Harrison et al. 1973) com formação de um composto tóxico, o N-3,5-dimetilfenil N-metilformamidina (Knowles \& Roulston 1973). Segundo Roy-Smith (1975), a contaminação de suspensões de amitraz com poluentes orgânicos provavelmente provoca acidificação do fluido, tendendo a induzir a hidrólise do acaricida. Embora muitos eqüinos sejam banhados com amitraz, a maior parte dos animais tratados com uma suspensão aquosa do produto a $0,025 \%$ não apresenta efeitos indesejáveis ou tem uma estase intestinal transitória (Seawright 1984, observações não publicadas). Além disso, o quadro de intoxicação que ocorre em alguns animais pode evoluir de maneira diferente. Em alguns casos, a impactação regride sem medicação, em outros, o tratamento sintomático é suficiente para restaurar o fluxo fecal após 24 a 48 horas, porém, em uma pequena parte dos casos, a impactação não responde à terapia (Roberts \& Seawright 1979).

Nos casos naturais de intoxicação descritos por Roberts \& Seawright (1979), Auer et al. (1984) e Mutsaers \& van der
Velden (1988), foram utilizadas soluções na concentração de 0,025\% (dose terapêutica indicada como carrapaticida para bovinos). Dos nove casos descritos por Dearo \& Gandolfi (1995), em apenas um há referência à concentração da solução utilizada. Neste caso, o animal foi aspergido duas vezes ao dia, durante quatro dias, com uma solução de amitraz a 0,028\%. Hugnet \& Cadoré (1995) descreveram nove casos de intoxicação em equiinos aspergidos com soluções concentradas entre 0,025 a $0,1 \%$.

Sellers et al. (1982) utilizaram a dose de $1 \mathrm{mg} / \mathrm{kg}$ (IV) de amitraz e constataram uma dissociação da motilidade intestinal entre as partes ventral e dorsal do cólon maior esquerdo de eqüinos. 0 mesmo efeito foi obtido com uma injeção intra-arterial de $0,1 \mathrm{mg} / \mathrm{kg}$ de amitraz, no ramo esquerdo da artéria ileo-cólica (Sellers et al. 1984).

O modelo de cólica por impactação, determinado pela administração de amitraz na dose de $1 \mathrm{mg} / \mathrm{kg}$ (IV), foi reproduzido por Roberts \& Argenzio (1986); houve regressão entre 8 e 22 horas após a administração; dois pôneis que receberam a dose de $2 \mathrm{mg} / \mathrm{kg}$ (IV) tiveram um quadro acentuado da intoxicação.

Em seus estudos sobre a farmacocinética e o metabolismo de amitraz em pôneis e ovelhas, Pass \& Mogg (1995) utilizaram as doses de $1,0 \mathrm{mg} / \mathrm{kg}$ e $0,68 \mathrm{mg} / \mathrm{kg}$ (IV) para amitraz e BTS 27271 (um dos metabólitos de amitraz), respectivamente. Foram produzidos quadros de sedação reversíveis pela administração de ioimbina, logo após o término do experimento.

Diminuição da atividade locomotora espontânea em eqüinos foi verificada após administração intravenosa de amitraz nas doses de 0,$05 ; 0,1$ e $0,15 \mathrm{mg} / \mathrm{kg}$ (Harkins et al 1997). As mesmas dosagens e via de administração foram utilizadas para caracterizar os efeitos antinociceptivo e sedativo do acaricida (Queiroz-Neto et al 1998).

\section{Sinais clínicos}

Roberts \& Seawright (1979) descrevem, nos casos de ocorrência espontânea, um quadro clínico caracterizado por sonolência, leve incoordenação, depressão, redução ou ausência dos ruídos intestinais, ausência de defecação e progressiva impactação do intestino grosso. Auer et al. (1984) relataram quadros de evolução subaguda, nos quais os animais se recuperaram, após tratamento sintomático, 7 dias depois do banho com o acaricida. Os sintomas consistiram de depressão, incoordenação, severa cólica por impactação com diminuição dos ruídos intestinais, taquicardia, mucosas congestas, desidratação, taquipnéia e constipação com eliminação de fezes firmes e ressecadas em pequena quantidade. $O$ exame de palpação retal revelou conteúdo de consistência firme no intestino grosso. Além disso, havia pouca ingestão de água e manifestações de dor como rolar. Um animal desenvolveu edema subcutâneo na face. Exames laboratoriais revelaram leucocitose, desidratação e acidose. Próximos à recuperação, os animais mostravam distensão abdominal e diarréia transitória.

O intervalo entre o início dos sintomas e o atendimento veterinário que variou de 1 a 10 dias, foi considerado por 
Dearo \& Gandolfi (1995) como período de evolução. Neste trabalho os proprietários mencionaram sinais como "pateamento", olhar para os flancos, rolar no solo, distensão abdominal, sudorese, ausência de defecação, depressão, decúbito prolongado, tremores musculares, anorexia e "brincar com água”. O exame clínico ainda revelou taquicardia, freqüência respiratória normal ou aumentada, temperatura retal entre 37 e $38,8^{\circ} \mathrm{C}$, tempo de preenchimento capilar (TPC) normal ou aumentado, congestão de mucosas e movimentos intestinais reduzidos ou ausentes. Refluxo nasogástrico após sondagem foi observado em poucos animais. À palpação retal constatou-se ausência ou pequena quantidade de fezes ressecadas, recobertas ou não por grande quantidade de muco, além de conteúdo intestinal compactado no cólon maior, em especial no cólon maior esquerdo. Ao descreverem nove casos de intoxicação por amitraz em eqüinos, Hugnet \& Cadoré (1995) referem-se a evolução de apenas um, em que um animal foi medicado com atipamezole três dias após manifestar sintomas, que regrediram em seis horas. Observou-se que sintomas de cólica estavam presentes em todos os animais atendidos, prostração em seis, anorexia, diminuição do trânsito digestivo e hipertermia em três, sudorese em dois e ataxia e decúbito em apenas um deles.

Roberts \& Seawright (1983), em publicação mais detalhada, afirmaram que com a dose de $1 \mathrm{mg} / \mathrm{kg}$ por via intravenosa (IV), ocorre uma síndrome espontaneamente reversível, caracterizada por tenesmo para urinar e defecar, sudorese, fasciculação muscular, aumentos transitórios na freqüência e amplitude da respiração e sinais nervosos como flacidez dos músculos da cabeça e pescoço, profunda depressão do sistema nervoso central (SNC), parada da mastigação com alimento na boca, ataxia e paresia de membros torácicos e pélvicos, hipotonicidade do focinho, lábio inferior, pálpebras, orelhas e esfíncter anal e protrusão do pênis. Além disso, foram observados redução e ausência dos ruídos intestinais, estridor respiratório associado à posição baixa da cabeça, edema facial e hipotermia; em alguns animais havia poliúria, conteúdo retal ressecado, firme e coberto por muco e conteúdo dos cólons maior e menor muito firmes. Uma síndrome mais grave que pode tornar-se irreversível foi reproduzida pela administração de $4 \mathrm{mg} / \mathrm{kg}$ (IV), ao longo de 24 horas. Nesta ocasião foram observados todos os sintomas citados anteriormente, além de picos descontínuos de pirexia e valores elevados de hematimetria, hemoglobina, hematócrito, proteínas plasmáticas totais e albumina. Numa fase posterior ocorreram uremia, aumento da bilirrubina indireta, hiperglicemia, hipocloremia, leve hipocalemia e progressiva leucocitose, neutrofilia com desvio para a esquerda e eosinopenia.

Alguns autores administraram, por via intravenosa, metabólitos de amitraz sendo eles BTS 28369, BTS 28997, BTS 24868, BTS 27919 e BTS 27271. Os dois primeiros, induziram a tenesmo e sedação transitórios, o segundo provocou, adicionalmente, incoordenação, perda do tônus do lábio inferior e alterações cardiovasculares caracterizadas por extremidades frias, mucosas hipóxicas, preenchimento capilar pobre e pulso fraco. BTS 24868 e BTS 27919 se mostraram inócuos, enquanto BTS 27271, provocou tenesmo, sonolên- cia, ataxia, hiperpnéia, sudorese, ruídos intestinais e defecação reduzidos, além disso, foram observados edema do focinho, mucosas pálidas e pulso de volume diminuído. Exames laboratoriais revelaram marcada diminuição do hematócrito, hemoglobina, hematimetria, neutrófilos, linfócitos e proteínas totais. Adicionalmente foi observada hiperglicemia (Roberts \& Seawright 1983). Apenas sedação foi relatada por Pass $\& \operatorname{Mogg}$ (1995) com a administração deste último metabólito.

\section{Patogenia}

Alguns mecanismos foram propostos com o intuito de explicar o modo de ação do amitraz. Uma diminuição da sensibilidade da placa motora à acetilcolina foi sugerida na primeira descrição da intoxicação em eqüinos (Roberts \& Seawright 1979).

A inibição da enzima monoaminoxidase (MAO, tipos A e B), que provocaria uma diminuição na metabolização da noradrenalina, também tem sido defendida como causa principal dessa intoxicação (Aziz \& Knowles 1973, 1992, Florio et al. 1993, Benezet \& Knowles 1976). A metabolização das catecolaminas e indolaminas necessita de uma desaminação oxidativa, processo enzimático realizado pelas monoaminoxidases (Sakate et al. 1992). A concentração destas duas formas de enzimas varia consideravelmente entre os tecidos de diversas espécies animais (Squires 1972). O bloqueio da MAO provoca um acúmulo de noradrenalina no citosol dos neurônios, inibindo a sua liberação. Aumento dos níveis de noradrenalina e dopamina, além de uma diminuição do nível de ácido homovanílico foram observados no encéfalo de ratos após a administração de amitraz, sugerindo um efeito inibitório sobre a MAO (Flório et al. 1993).

Outro mecanismo de ação proposto, e hoje aceito por muitos pesquisadores, é o da estimulação de receptores $\mathrm{a}_{2}$ adrenérgicos. No sistema nervoso central (SNC) estes receptores estão localizados nas membranas pós-sinápticas dos neurônios adrenérgicos, sendo a regulação do tônus adrenérgico do sistema nervoso autônomo (SNA), uma de suas funções fisiológicas (Quadro 1). A estimulação desses receptores resulta em decréscimo da atividade simpática periférica e, conseqüientemente, no aparecimento de hipotensão e sedação (Goldberg \& Robertson 1983). Em 1984 demonstrouse que as alterações da motilidade intestinal causadas por amitraz eram prevenidas pela administração de ioimbina, um antagonista $\mathrm{a}_{2}$-adrenérgico específico (Sellers et al. 1984). O mesmo antagonista reduziu significativamente efeitos referentes ao SNC, tais como sonolência, ataxia e parada da mastigação (Roberts \& Argenzio 1986). Vários autores afirmam que a administração de antagonistas $\mathrm{a}_{2}$-adrenérgicos como a ioimbina e o atipamezole são capazes de reverter os efeitos provocados pelo amitraz (Schaffer et al. 1990; Hovda \& McManus 1993, Duncan 1993, Pass \& Mogg 1995, Hugnet \& Cadoré 1995, Hugnet et al. 1996, Harkins et al. 1997, Queiroz-Neto et al. 1998). Desta maneira, parece bem clara a função agonista $\mathrm{a}_{2}$-adrenérgica exercida pelo acaricida.

Sabe-se que a necessidade energética nos eqüinos é suprida, em sua maior parte, pela produção de ácidos graxos 
voláteis oriundos da digestão microbiana que ocorre no ceco e no cólon maior. Para que este processo ocorra satisfatoriamente, a ingesta deve ser constantemente misturada e retida por um longo período (aproximadamente 72 horas) nestes segmentos do intestino. Esta retenção é o resultado da coordenação entre os movimentos de propulsão e retropulsão (Clark 1990), que originam-se em determinadas regiões da parede do intestino grosso denominadas de marcapasso. Essas estruturas estão presentes no ceco, no cólon ventral direito e na flexura pélvica (Reed \& Bayly 2000). Sellers et al. (1982) verificaram alterações do peristaltismo na área da flexura pélvica após administração de amitraz, sugerindo uma alteração no marcapasso desta região. Dois anos depois observou-se que esses efeitos eram prevenidos pela administração de ioimbina, um antagonista $\mathrm{a}_{2}$-adrenérgico (Sellers et al. 1984). Tais alterações do peristaltismo associadas a uma maior absorção de fluidos no intestino seriam responsáveis pela formação da impactação intestinal (Roberts \& Seawright 1983, Roberts \& Argenzio 1986).

Uma maior permanência do amitraz no plasma de eqüinos pode ter relação com a maior susceptibilidade da espécie equiina à intoxicação por amitraz (Pass \& Mogg 1995).

Outros mecanismos de ação propostos para o amitraz referem-se à inibição da síntese de prostaglandinas e ao bloqueio de receptores $\mathrm{H}_{1}$ (Pass \& Seawright 1995).

\section{MATERIAL E MÉTODOS}

Experimentação

O delineamento experimental juntamente com dados relativos ao início dos sintomas, a evolução e ao desfecho, constam no Quadro 1 ( Resultados).

Animais. Foram utilizados 20 eqüinos $(17$ experimentos e 3 casos naturais) e 1 asinino, de ambos os sexos, com pesos variando de 160 a $350 \mathrm{~kg}$. A determinação da idade foi efetuada em cinco animais, por exame da arcada dentária, variando entre dois e dez anos. O peso dos eqüinos foi estimado por avaliação visual, exceto nos eqüinos 16, 17, 18 e 19, para os quais foi utilizada balança. Após vermifugação, os animais foram mantidos nos pastos adjacentes ao biotério, constituídos em sua maior parte por "grama-batatais" (Paspalum notatum).

Local. Os experimentos foram realizados nas instalações do biotério do Projeto Sanidade Animal (PSA) - Embrapa/UFRRJ, Seropédica, RJ.

Doses e vias de administração do amitraz. Três eqüinos $(1,2$ e 3) e um asinino receberam, por via oral, doses diárias que variaram de $1 \mathrm{a} 36,4 \mathrm{mg} / \mathrm{kg}$ durante 1 a 34 dias de amitraz ${ }^{7}$ sob forma de soluções aquosas em concentrações que variaram de 20,8 a $56,8 \mathrm{mg} /$ $\mathrm{ml}$ (acrescidas de aproximadamente $10 \mathrm{~g}$ de açúcar refinado para melhorar a palatabilidade), administrada com o auxílio de seringa de vidro de $20 \mathrm{ml}$. O Eqüino 1 recebeu trinta e quatro vezes, num período de 5 meses e meio, por via oral, dosagens que variaram de 1 a $25 \mathrm{mg} / \mathrm{kg}$, o Eqüino 2 a dose de $5,8 \mathrm{mg} / \mathrm{kg}$ duas vezes, num período de três dias, o Eqüino 3 a dose única de $5,5 \mathrm{mg} / \mathrm{kg}$ e o Asinino doses variando de 7,2 a $36,4 \mathrm{mg} / \mathrm{kg}$ em cinco aplicações num período de 7 dias. Nos experimentos com o Eqüino 1 e Asinino, a dose foi aumentada de acordo com a regressão dos sintomas. As doses

\footnotetext{
${ }^{7}$ Triatox, Coopers.
}

repetidas eram dadas mesmo que os animais já apresentassem sintomas da intoxicação; porém nos dias em que ocorreram sintomas graves da intoxicação, a administração da droga foi suspensa. $O$ Eqüino1 recebeu, por via oral, as soluções SPMA e SPAA1, os Eqüinos 2, 3 e o Asinino, somente a solução preparada no momento da utilização (SPMA).

Outros catorze animais (Eqüinos 4, 5, 6, 7, 8, 9, 10, 11, 12, 13, $16,17,18$ e 19) e também o Eqüino 1, foram aspergidos com soluções aquosas de amitraz, em concentrações variando de 0,025 a $0,2 \%$.

$O$ Equiino 1 recebeu, por meio de banhos de aspersão (BA), as soluções SPMA em concentrações de 0,025 a $0,0375 \%$. Nos Eqüinos $4,5,6,7,8,9,10,11,12$ e 13 , da mesma maneira aplicaram-se soluções SPMA na concentração de $0,025 \%$. Os Eqüinos 5 e 6 foram aspergidos também com a solução preparada 21 dias antes da aplicação (SPAA2) a 0,025 e 0,05\%. Os Eqüinos 16 e 17 receberam, por esta mesma via, soluções SPMA a $0.1 \%$ e os Eqüinos 18 e 19, soluções SPMA a $0,2 \%$.

O Eqüino 1 recebeu ainda, por via oral, uma solução preparada 8 a 12 dias antes da aplicação (SPAA1).

Exame clínico. Os animais foram examinados uma vez ao dia, e quando apresentaram sintomas, a freqüência dos exames foi aumentada chegando-se ao acompanhamento contínuo quando necessário. Foram avaliados comportamento, postura, frequiências cardíaca (FC) e respiratória (FR), aspecto das mucosas, tempo de preenchimento capilar em segundos (TPC), temperatura retal (T), motilidade intestinal (MI) e aspecto das fezes, bem como algumas alterações do sistema nervoso. Os Eqüinos 16, 17, 18 e 19 foram submetidos a exame clínico mais detalhado.

\section{Casos Naturais}

Nos três casos de intoxicação natural incluídos neste trabalho, os eqüinos eram oriundos, do Setor de Guarda da Universidade Federal Rural do Rio de Janeiro (Equiino 14) e da Fazenda Vale do Sol situada na Estrada da Conceição 5, Cacaria, Piraí, RJ (Eqüino 15). O Eqüino 14 foi encaminhado ao Biotério do PSA Embrapa/UFRRJ, Seropédica, RJ, onde permaneceu até morrer. O Eqüino 15 foi atendido na propriedade e examinado em duas ocasiões, seguindose os parâmetros avaliados anteriormente com adição do exame de palpação retal. (vide protocolos para maiores detalhes). O Eqüino 20 foi atendido pela Central de Diagnóstico Veterinário (Cedivet) da Universidade Federal do Pará, no Município de Castanhal, PA, onde permaneceu até ser sacrificado in extremis.

\section{RESULTADOS}

No Quadro 1 constam, além do delineamento experimental, os dados sobre o início dos sintomas após a administração/ aplicação do amitraz, a evolução da intoxicação e o desfecho, tanto dos casos experimentais quanto naturais.

\section{Casos experimentais}

Início dos sintomas e evolução. Afora o experimento com o Eqüino 1, nos experimentos em que o amitraz foi dado por via oral, o início dos sintomas variou entre 15 minutos e 2 horas após a primeira administração. A evolução nesses casos variou de 3 a 9 dias. Nos experimentos em que o amitraz foi aplicado por aspersão, este prazo foi de 6 horas e 28 minutos a 8 horas e 38 minutos. A evolução nesses últimos casos foi de 5 a 6 dias.

No Eqüino 1, no experimento em que o amitraz foi aplicado por via oral, em 34 doses, em um período pouco superior 

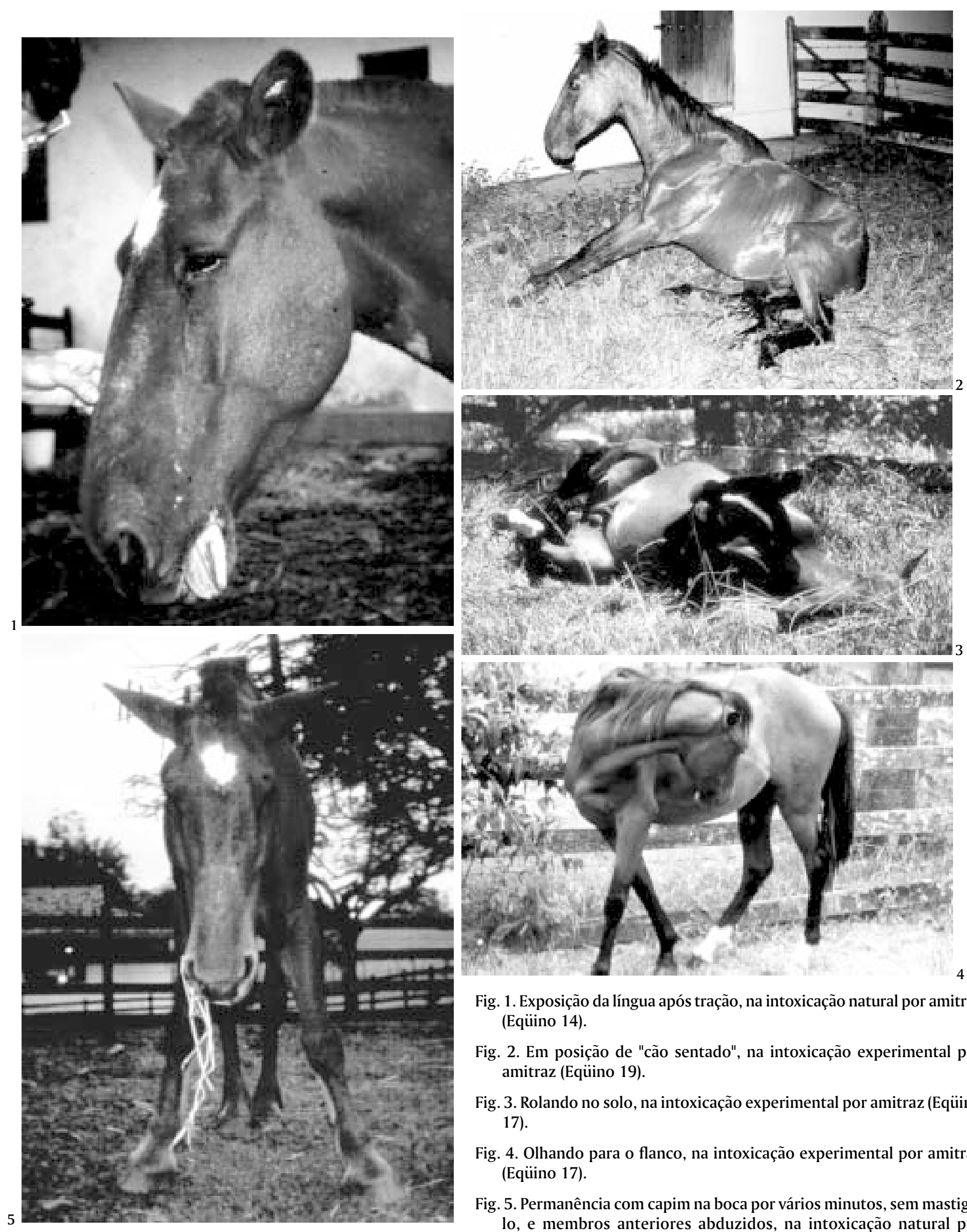

Fig. 1. Exposição da língua após tração, na intoxicação natural por amitraz (Eqüino 14).

Fig. 2. Em posição de "cão sentado", na intoxicação experimental por amitraz (Eqüino 19).

Fig. 3. Rolando no solo, na intoxicação experimental por amitraz (Eqüino 17).

Fig. 4. Olhando para o flanco, na intoxicação experimental por amitraz (Eqüino 17).

Fig. 5. Permanência com capim na boca por vários minutos, sem mastigálo, e membros anteriores abduzidos, na intoxicação natural por amitraz (Eqüino 14). 
a 5 meses, o início dos sintomas foi de 5 dias após a primeira administração. $\mathrm{O}$ animal adoeceu diversas vezes mostrando sintomas durante 2 a 23 dias. No experimento em que o amitraz foi aplicado por aspersão o animal adoeceu somente após a primeira das três aplicações e os primeiros sintomas ocorreram 70 horas após a aspersão. Nesta ocasião mostrou sintomas de intoxicação por 24 dias.

Sinais clínicos. As principais alterações clínicas encontradas nos experimentos referem-se aos sistemas nervoso ( $\mathrm{SN}$ ) e digestivo (esses dados podem ser encontrados nos Quadros 2 e 3) e, com menor intensidade, aos sistemas circulatório e respiratório, além de alterações do estado geral.

As principais alterações clínicas observadas no sistema circulatório foram taquicardia $(8 / 8)$, aumento do tempo de preenchimento capilar $(6 / 7)^{8}$ e mucosas congestas $(6 / 8)$. No sistema respiratório evidenciou-se estridor (5/8), taquipnéia (5/8), dispnéia $(5 / 8)$, secreção nasal $(4 / 8)$, bradipnéia $(4 / 8)$ e respiração abdominal (4/8). Além disso, ocorreram alterações do estado geral como apatia (8/8) e hipotermia (5/8).

\section{Casos naturais}

Todos os casos naturais ocorreram após aspersão do amitraz. Os primeiros sintomas foram observados 2 e 3 dias após o banho. A evolução foi de 6,7 e 17 dias. Um animal (Eqüino 14) manifestou principalmente os sinais referentes ao sistema nervoso, observados nos experimentos, com exceção dos sinais de cruzamento dos membros ao caminhar, bocejos, lábios flácidos e exposição da língua e do pênis. O outro animal (Eqüino 15) manifestou somente sintomas digestivos como rolar, patear, hipomotilidade/atonia intestinal e impactação do intestino grosso. 0 terceiro animal (Eqüino 20), inicialmente evidenciou sintomas digestivos caracterizados por patear, rolar, atonia intestinal e impactação do conteúdo do intestino grosso, com conseqüente desenvolvimento de laminite; na fase final exibiu acentuada sintomatologia nervosa mostrando compressão da cabeça contra obstáculos, incoordenação motora com cruzamento dos membros ao caminhar e relutância em se movimentar.

\section{DISCUSSÃO E CONCLUSÕES}

\section{Aspectos toxicológicos}

No presente estudo foi possível induzir experimentalmente o quadro de intoxicação por amitraz em equiídeos. Não considerando o caso do Eqüino 1, bastante atípico, no caso da administração por via oral, os primeiros sintomas foram observados um pouco mais rapidamente (15 min. a $2 \mathrm{~h} 05 \mathrm{~min}$.) do que quando o amitraz foi aplicado por aspersão $(6 \mathrm{~h} 28 \mathrm{~min}$. a $8 \mathrm{~h} 38 \mathrm{~min}$.). A evolução do quadro clínico foi subaguda, tanto no caso da administração por via oral (4-9 dias), como no da aplicação por aspersão (5-6 dias). Só morreram animais que receberam amitraz por via oral. Um animal que $o$ amitraz foi aplicado por aspersão, foi sacrificado.

No caso do Eqüino 1, o início dos sintomas após a administração oral (5 dias) e após a aspersão (70 horas) ocorreu

\footnotetext{
${ }^{8}$ Alteração presente em 6 dos 7 casos em que foi avaliada.
}

mais tarde. Provavelmente a razão disso foi o uso inicial de dosagens muito baixas. A evolução, após a aspersão também foi mais longa (24 dias) e por via oral foi em parte também mais longa ( 2 a 13 dias). Nesse caso foi utilizada a via oral,, no intuito de reproduzir, com maior eficácia e rapidez, o quadro clínico da intoxicação. Por outro lado, os eqüinos aspergidos com soluções a 0,1 e $0,2 \%$, manifestaram sintomas semelhantes por 5 a 6 dias caracterizando quadro de evolução subaguda semelhante ao observado nos casos naturais descritos por Auer et al. (1984). 0 eqüino 1 , aspergido em três ocasiões, com soluções a 0,025 e $0,037 \%$, apresentou um quadro de evolução crônica manifestando sintomas por 24 dias. Os outros 10 animais (eqüinos 4 a 13), banhados por aspersão com soluções recém-preparadas $(0,025 \%)$, não adoeceram, fato em concordância com as observações de que a maior parte dos eqüinos banhados com uma suspensão aquosa a $0,025 \%$ não apresenta quaisquer sintomas ou tem apenas estase intestinal transitória (Seawright 1984, observações não-publicados).

Nos casos naturais descritos neste estudo observaram-se quadros de evoluções subaguda e crônica (6, 7 e 17 dias).

Uma possível maior toxicidade de soluções de amitraz preparadas com antecedência, proposta por Auer et al. (1984) não pode ser comprovada em nosso estudo.

O Eqüino 1, em várias ocasiões e com diferentes dosagens, demonstrava sintomas acentuados da intoxicação. Estes, após alguns dias de administração da mesma dose regrediam e por vezes desapareciam; Quando se aumentava a dose, novamente ocorriam de forma acentuada. Acreditamos que esse animal tenha desenvolvido crescente tolerância ao amitraz.

Os Eqüinos 16, 17 e 18, aspergidos com soluções de amitraz a $0,1 \%$ e $0,2 \%$, se recuperaram de forma espontânea, ao contrário do referido por Roberts \& Seawright (1983). Não dispomos de dados suficientes neste estudo para esclarecer este ponto, mas uma maior susceptibilidade de alguns animais à droga pode estar envolvida.

Acreditamos que erros na preparação de soluções carrapaticidas à base de amitraz que aumentem a concentração das mesmas, possivelmente sejam fator importante na ocorrência dos episódios de intoxicação natural, embora o uso de soluções a $0,025 \%$ (dose terapêutica para bovinos) também possa provocar, em alguns animais, sintomas da intoxicação.

\section{Sinais clínicos}

Os principais sinais clínicos observados neste trabalho referem-se aos sistemas nervoso e digestivo e, em menor grau, aos sistemas circulatório e respiratório.

Os animais que receberam o amitraz por via oral, manifestaram sintomas graves relativos aos sistemas digestivo e nervoso. Quadro semelhante foi observado nos animais aspergidos com soluções de amitraz a $0,2 \%$. Os eqüinos aspergidos com soluções de amirtraz a $0,1 \%$ também mostraram sinais digestivos acentuados, porém os sintomas nervosos foram menos intensos nesse grupo.

A administração do amitraz por via oral produziu sintomas semelhantes aos observados por Roberts \& Seawright (1983) em eqüinos que receberam a droga por via intravenosa. 
Quadro 1. Intoxicação por amitraz em equiídeos. Delineamento experimental e principais dados sobre a intoxicação natural

\begin{tabular}{|c|c|c|c|c|c|c|c|c|}
\hline Animal & Peso & $\begin{array}{c}\text { Via e } \mathrm{n}^{\circ} \\
\text { de admi- } \\
\text { nistrações }\end{array}$ & $\begin{array}{l}\text { Dose diária (PO) ou } \\
\text { concentração (BA) }\end{array}$ & $\begin{array}{c}\text { Solução } \\
\text { administrada }\end{array}$ & $\begin{array}{l}\text { Período das } \\
\text { adminis- } \\
\text { trações }\end{array}$ & $\begin{array}{l}\text { Início dos sinto- } \\
\text { mas apósa } 1^{\mathrm{a}} \\
\text { administração }\end{array}$ & Evolução & Desfecho \\
\hline \multicolumn{9}{|l|}{ Experimentos } \\
\hline \multirow[t]{2}{*}{ Eqüino 1} & $250 \mathrm{~kg}$ & $\mathrm{BA}-3$ & $\mathrm{BA}^{\mathrm{a}} 0,025 \%$ е $0,0375 \%$ & BA - SPMA ${ }^{\mathrm{C}}$ & 29/07 a 02/09/92 & $\mathrm{BA}-70$ horas & BA - 24 dias & BA - Recuperou-se \\
\hline & $\mathrm{PO}-34$ & & $\mathrm{PO}^{\mathrm{b}} 1$ a $25 \mathrm{mg} / \mathrm{Kg}$ & PO - SPMA e SPAA $1^{d}$ & $11 / 05$ a $29 / 10 / 94$ & PO - 5 dias & $\mathrm{PO}-02$ a $23 \operatorname{dias}^{\mathrm{e}}$ & PO - Morreu ${ }^{f}$ \\
\hline Eqüino 2 & $250 \mathrm{~kg}$ & $\mathrm{PO}-2$ & $5,8 \mathrm{mg} / \mathrm{Kg}$ & SPMA & 25 а $27 / 10 / 94$ & 50 minutos & 4 dias & Morreu \\
\hline Eqüino 3 & $300 \mathrm{~kg}$ & $\mathrm{PO}-1$ & $5,5 \mathrm{mg} / \mathrm{Kg}$ & SPMA & 14/03/95 & 15 minutos & 3 dias & Morreu \\
\hline Eqüino 4 & $350 \mathrm{~kg}$ & BA -2 & $0,025 \%$ i & SPMA & 18 a $25 / 04 / 95$ & - & - & Não adoeceu \\
\hline Eqüino 5 & $350 \mathrm{~kg}$ & $\mathrm{BA}-4$ & 0,025 e $0,05 \%$ & SPMA e SPAA2 ${ }^{g}$ & $18 / 04$ a $19 / 07 / 95$ & - & - & Não adoeceu \\
\hline Eqüino 6 & $350 \mathrm{~kg}$ & $\mathrm{BA}-4$ & 0,025 e $0,05 \%$ i & SPMA e SPAA2 & $18 / 04$ a $19 / 07 / 95$ & - & - & Não adoeceu \\
\hline Eqüino 7 & $350 \mathrm{~kg}$ & BA -2 & $0,025 \%$ & SPMA & 18 a $25 / 04 / 95$ & - & - & Não adoeceu \\
\hline Eqüino 8 & $250 \mathrm{~kg}$ & $\mathrm{BA}-1$ & $0,025 \% \mathrm{i}$ & SPMA & $27 / 07 / 95$ & - & - & Não adoeceu \\
\hline Eqüino 9 & $250 \mathrm{~kg}$ & $\mathrm{BA}-1$ & $0,025 \% \mathrm{i}$ & SPMA & $27 / 07 / 95$ & - & - & Não adoeceu \\
\hline Eqüino 10 & $250 \mathrm{~kg}$ & $\mathrm{BA}-1$ & $0,025 \% \mathrm{i}$ & SPMA & $27 / 07 / 95$ & _- & _- & Não adoeceu \\
\hline Eqüino 11 & $250 \mathrm{~kg}$ & $\mathrm{BA}-1$ & $0,025 \% \mathrm{i}$ & SPMA & $27 / 07 / 95$ & - & - & Não adoeceu \\
\hline Eqüino 12 & $250 \mathrm{~kg}$ & $\mathrm{BA}-1$ & $0,025 \% \mathrm{i}$ & SPMA & $27 / 07 / 95$ & _- & _- & Não adoeceu \\
\hline Eqüino 13 & $250 \mathrm{~kg}$ & $\mathrm{BA}-1$ & $0,025 \% \mathrm{i}$ & SPMA & $27 / 07 / 95$ & - & - & Não adoeceu \\
\hline Eqüino 16 & $238 \mathrm{~kg}$ & $\mathrm{BA}-1$ & $0,1 \% \mathrm{j}$ & SPMA & $17 / 01 / 01$ & $<7$ horas & 5 dias & Recuperou-se \\
\hline Eqüino 17 & $226 \mathrm{~kg}$ & $\mathrm{BA}-1$ & $0,1 \% \mathrm{j}$ & SPMA & $17 / 01 / 01$ & $<6 \mathrm{~h}$ e $28 \mathrm{~min}$. & 5 dias & Recuperou-se \\
\hline Eqüino 18 & $180 \mathrm{~kg}$ & $\mathrm{BA}-1$ & $0,2 \%$ & SPMA & $17 / 02 / 01$ & $<8 \mathrm{~h}$ e $38 \mathrm{~min}$. & 6 dias & Recuperou-se \\
\hline Eqüino 19 & $220 \mathrm{~kg}$ & $\mathrm{BA}-1$ & $0,2^{\circ} \mathrm{j}$ & SPMA & $17 / 02 / 01$ & $<7 \mathrm{~h}$ e $27 \mathrm{~min}$. & 5 dias & Sacrificado \\
\hline Asinino & $160 \mathrm{~kg}$ & $\mathrm{PO}-5$ & 7,2 a $36,4 \mathrm{mg} / \mathrm{Kg}$ & SPMA & $25 / 10$ a $02 / 11 / 94$ & 2 h e $5 \mathrm{~min}$. & 9 dias & Morreu \\
\hline \multicolumn{9}{|l|}{ Casos naturais } \\
\hline Eqüino 14 & $350 \mathrm{~kg}$ & $\mathrm{BA}-1$ & Desconhecida & Desconhecida & - & Desconhecido & $17 \operatorname{dias}^{\mathrm{h}}$ & Morreu \\
\hline Eqüino 15 & $300 \mathrm{~kg}$ & $\mathrm{BA}-1$ & Desconhecida & SPMA & $18 / 11 / 99$ & 3 dias & 6 dias & Recuperou-se \\
\hline Eqüino 20 & $300 \mathrm{~kg}$ & BA - 2 & Desconhecida & SPMA & 02 а $03 / 08 / 02$ & 2 dias & 7 dias & Sacrificado \\
\hline \multicolumn{5}{|c|}{$\begin{array}{l}\text { aBA - Banhos por aspersão. } \\
\text { bPO - Via oral. } \\
\text { cSPMA - Solução preparada no momento da administração. } \\
\text { dSPAA1 - Solução preparada } 8 \text { a } 12 \text { dias antes da administração. } \\
\text { 'e Com doses menores ( até } 2,5 \mathrm{mg} / \mathrm{kg} \text { ), inicialmente mostrava sin- } \\
\text { tomas da intoxicação e em poucos dias se recuperava. }\end{array}$} & \multicolumn{4}{|c|}{$\begin{array}{l}\text { gSPAA2 - Solução preparada } 21 \text { dias antes da administração. } \\
\text { hPeríodo em que permaneceu no PSA-Embrapa,RJ. } \\
\text { iForam utilizados sete litros da solução. } \\
\text { jForam utilizados cinco litros da solução. }\end{array}$} \\
\hline
\end{tabular}

Os Eqüinos 18 e 19, aspergidos com soluções aquosas do acaricida a $0,2 \%$, manifestaram sinais neurológicos acentuados, semelhantes aos que receberam o amitraz por via oral. Até o presente momento, não existe descrição de experimentos que tenham utilizado soluções nesta concentração $(0,2 \%)$.

Nos casos naturais (Eqüinos 14, 15 e 20), somente os Equiinos 14 e 20 demonstraram sinais neurológicos dignos de nota, por sinal muito semelhantes aos manifestados pelos Equiinos 1, 2, 3, 18 e 19 e pelo asinino, intoxicados experimentalmente. Adicionalmente, o Eqüino 14 apresentava hipermetria e mastigação vazia e o eqüino 20 , compressão da cabeça contra obstáculos, sintomas esses ainda não descritos na intoxicação por amitraz.

Diante dos sinais nervosos observados em nossos experimentos, podemos inferir os possíveis locais afetados no Sistema nervoso.

Alterações no estado de consciência como sonolência e depressão se originam de lesão focal ou difusa no telencéfalo e diencéfalo e no tronco encefálico, mais precisamente no sistema reticular ativador ascendente (SRAA) (Mayhew 1989). Bocejos são considerados por Mayhew (1989) como alterações sutis do comportamento e sinais de doença do córtex.

Distúrbios dos nervos cranianos foram evidentes neste trabalho. Manifestações clínicas como ptose palpebral, auricular e labial, flacidez labial e dificuldade de apreensão do alimen- to, indicam distúrbio no nervo facial ou em seu núcleo no bulbo; a diminuição ou ausência dos reflexos de ameaça, palpebral, auricular, e do lábio superior também ocorrem com lesões nesses mesmos locais, uma vez que o nervo facial compõe a via motora destes reflexos. Esses três últimos reflexos, juntamente com o RPL e RLI, têm a sua via aferente composta por ramos sensitivos do nervo trigêmio e seu núcleo sensitivo localizado na ponte; lesões destas estruturas podem, da mesma forma, afetá-los, além de provocar diminuição da sensibilidade cutânea na cabeça (De Lahunta 1983, Mayhew 1989, Dirksen et al. 1993). Acreditamos que a diminuição do reflexo de ameaça deva-se a uma lesão da sua via eferente. A exposição da língua, bem como a diminuição ou ausência do reflexo lingual pode ser causada por lesão do nervo hipoglosso ou do seu núcleo (Mayhew 1989), localizado no bulbo (De Lahunta 1983). Doenças cerebrais podem resultar em flacidez da língua e o animal pode permanecer com a mesma para fora da boca, porém, nestes casos, não há paralisia flácida, já que apenas o neurônio motor superior está acometido pela lesão (Mayhew 1989). A dificuldade de mastigação, bem como a diminuição do reflexo palatal, podem ser provocadas por alterações na sua via aferente composta pelos ramos sensitivos do nervo trigêmio, gânglio trigeminal, trato espinhal do nervo trigêmio no bulbo e primeiro segmento cervical, núcleo sensitivo pontino e núcleo do trato espinhal do nervo trigêmio no bulbo e no 


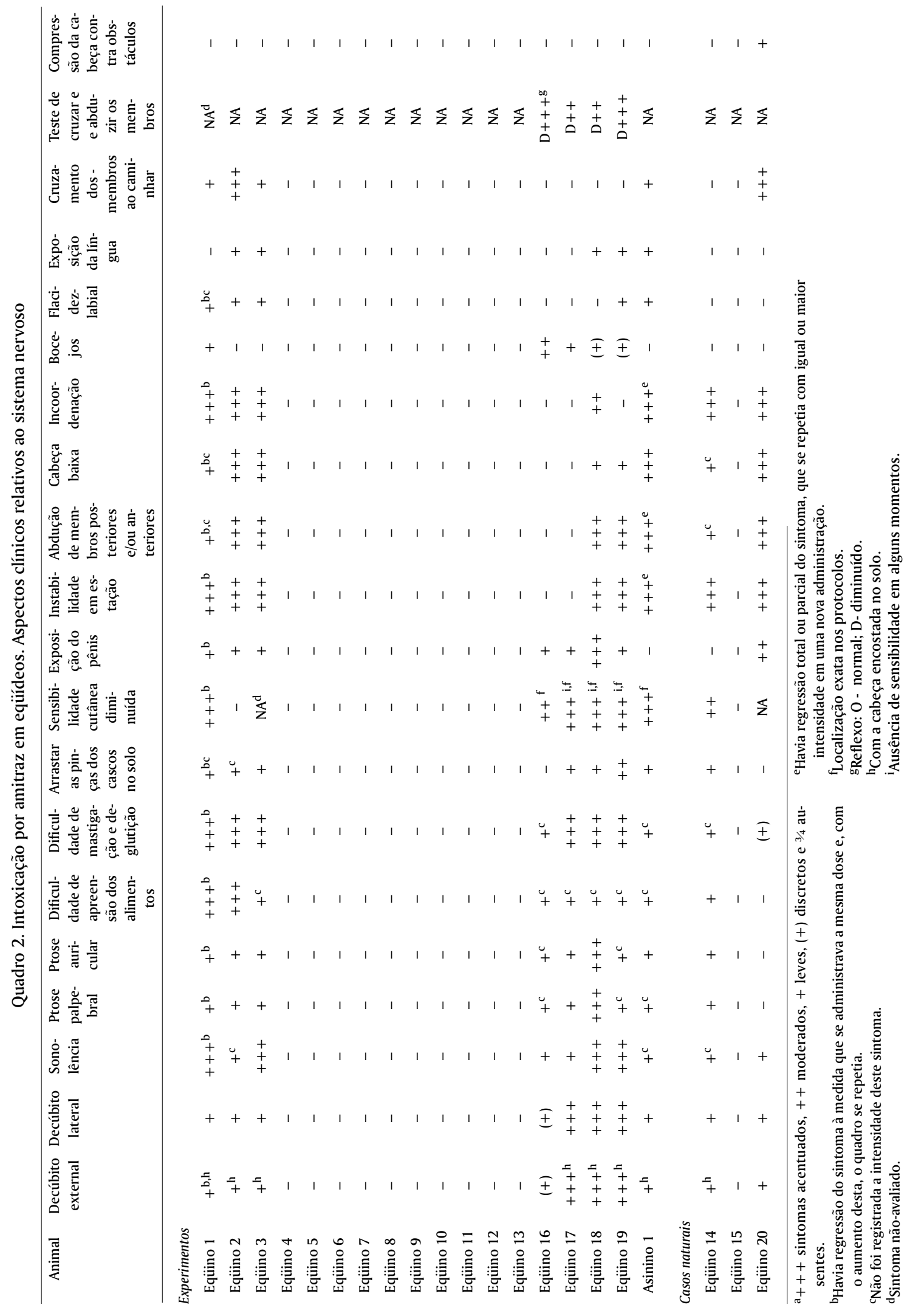




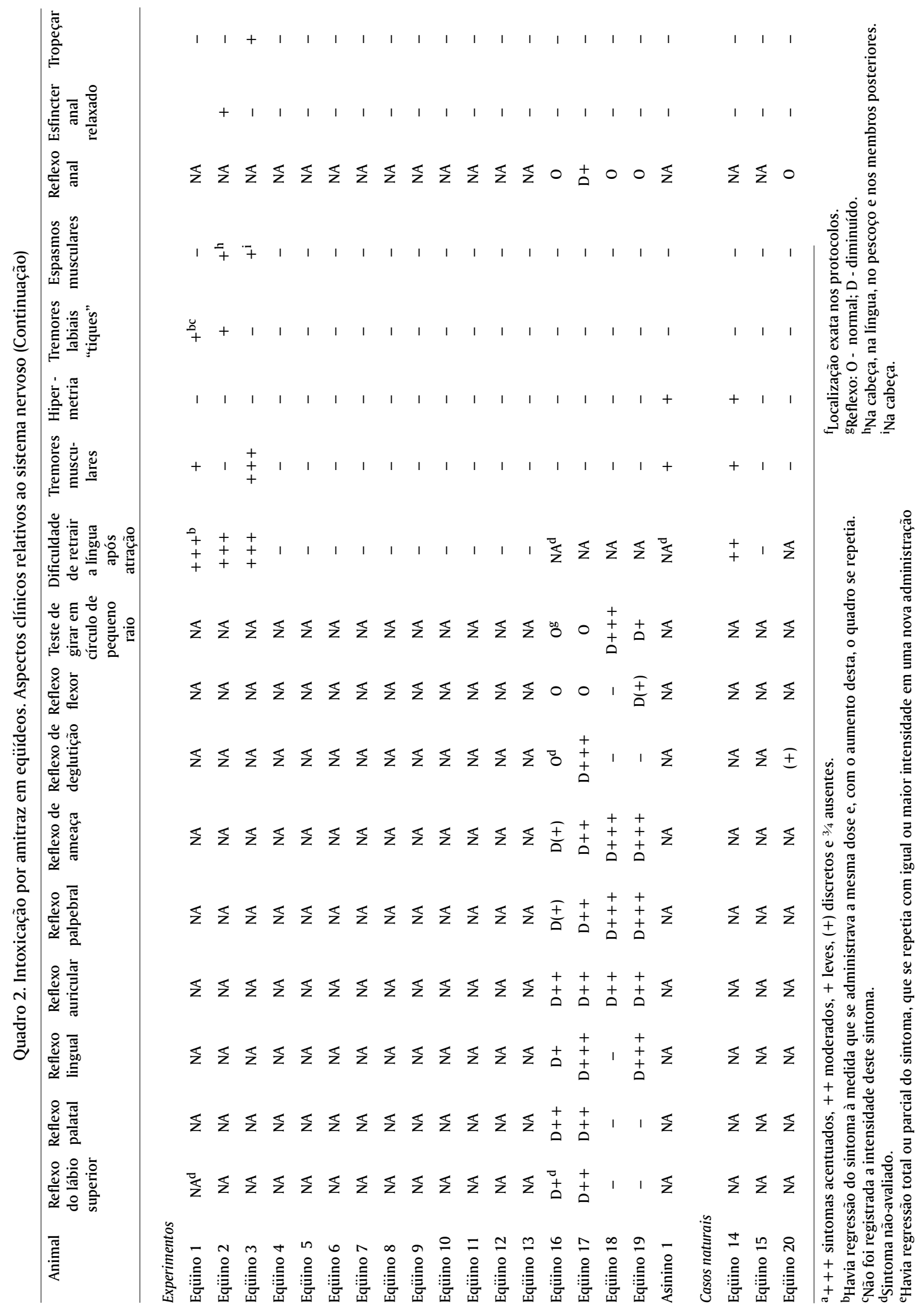


Intoxicações natural e experimental por amitraz em eqüídeos: aspectos clínicos

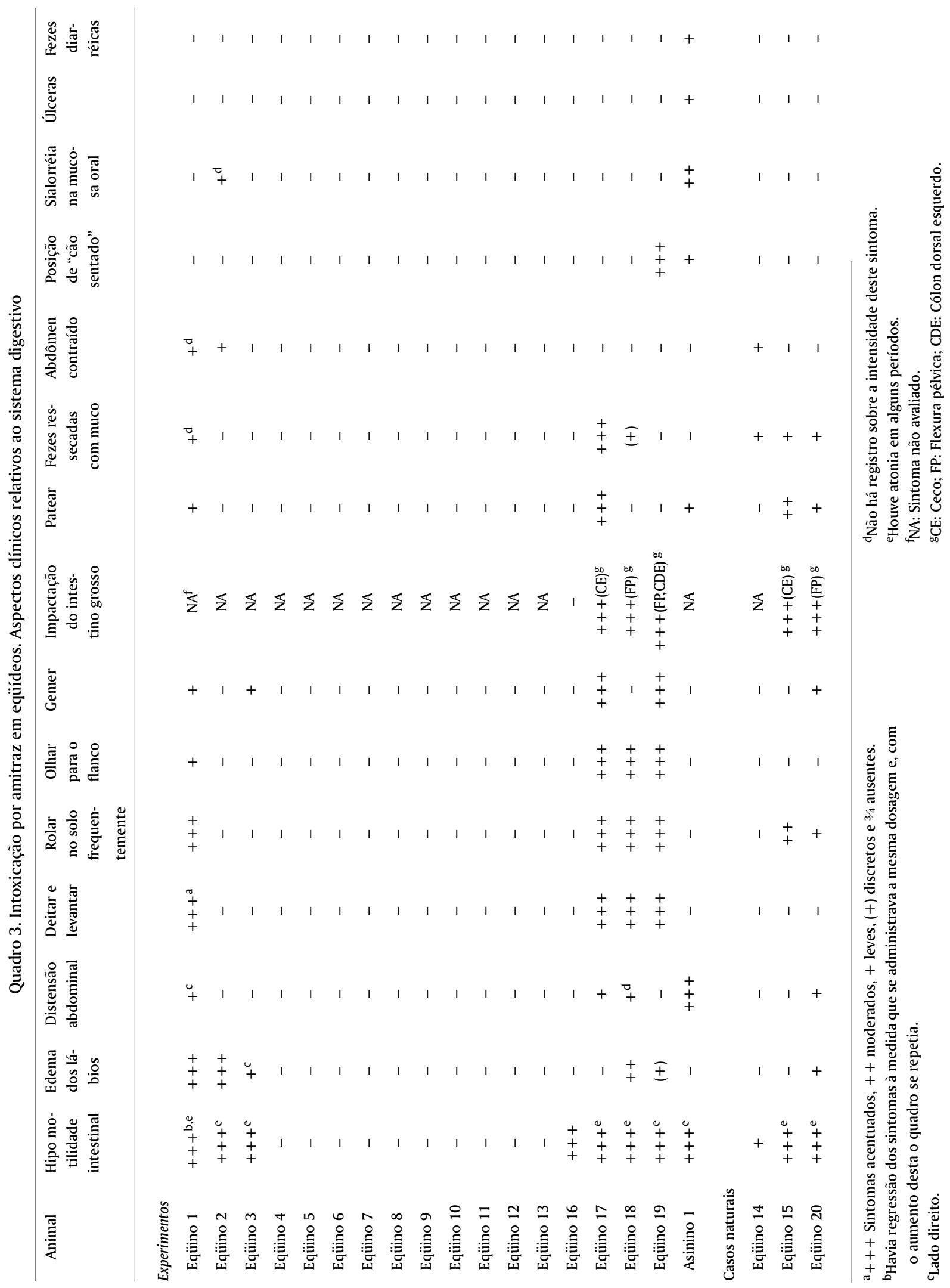

Pesq. Vet. Bras. 23(3):105-118, jul./set. 2003 
primeiro segmento cervical; ou ainda na via eferente composta pelos núcleos do nervo facial e motor do nervo trigêmio localizados no bulbo e na ponte, respectivamente, e pelos nervos facial e trigêmio (De Lahunta 1983). Também foram observados dificuldade de deglutição e diminuição do reflexo de deglutição (ver quadro 3), a via aferente é a mesma do reflexo palatal, a via eferente é composta pelos nervos glosso-faríngeo e vago e pelo núcleo ambíguo no bulbo. Lesões nestes locais causam graus variados de disfagia (De Lahunta 1983). Paralisia trigeminal motora, facial bilateral ou hipoglossal também resultam em disfagia neurológica (Mayhew 1989). Devemos ressaltar que quando excluímos da discussão de possíveis locais de lesões a junção neuro-efetora e aos respectivos músculos, o fizemos por evidenciar clinicamente que estes locais não foram afetados, uma vez que os animais manifestaram alterações do estado de consciência, o que não ocorre nas doenças que afetam a junção neuro-efetora como o botulismo, e não mostraram sinais de doença muscular (Radostits et al. 2002).

A postura em estação com a cabeça baixa, provocada por um relaxamento da musculatura cervical (Queiroz-Neto et al. 1998) pode originar-se, em nossa opinião, de um distúrbio da propriocepção geral da região cervical. Este distúrbio também pode ser a causa da postura com a cabeça apoiada no solo, quando em decúbito esternal. Em ambos os casos poderia estar afetada principalmente a via cervico-espinocerebelar. Distúrbios desta via, da via cuneocerebelar e ainda do trato espinocerebelar rostral alteram a regulação do tônus muscular exercida pelo cerebelo (De Lahunta 1983). Outros sinais como permanência em estação com os membros abduzidos, instabilidade em estação, cruzar os membros ao caminhar, hipermetria, diminuição das respostas posturais aos testes de cruzar e abduzir os membros, dificuldade de girar em círculo de pequeno raio e diminuição da força muscular, traduzida por um deslocamento mais fácil da região posterior do animal, quando este era tracionado pela cauda, indicam distúrbio da propriocepção. Poderiam estar afetadas as vias proprioceptivas cerebelares reflexas do tronco e dos membros pélvicos, bem como dos membros torácicos e as vias proprioceptivas para a percepção consciente no córtex somestético (De Lahunta 1983).

O sinal clínico de arrastar as pinças dos cascos no solo é interpretado por Speirs (1999) como indicativo de paresia; por outro lado De Lahunta (1983) afirma que os animais com um distúrbio da propriocepção geral podem caminhar sobre a superfície dorsal de suas extremidades distais. Segundo este autor, pode ser difícil distinguir clinicamente paresia de deficiência proprioceptiva, mas ele afirma que normalmente isto não interfere na localização da lesão, uma vez que os sistemas do neurônio motor superior e da propriocepção geral estão muito próximos na maior parte do neuroeixo (medula espinhal, rombencéfalo, mesencéfalo e diencéfalo). Com relação à ausência do reflexo de retirada devemos considerar que o amitraz, quando aplicado na dose de $0,15 \mathrm{mg} / \mathrm{kg}$ por via intravenosa produz, além de sedação, um efeito antinociceptivo (QueirozNeto et al. 1998). Acreditamos que esse efeito antinociceptivo, observado também em nossos experimentos possa estar relacionado a distúrbios nas vias para percepção consciente da dor, bem como da via reflexa para os sistemas aferente e eferente somático geral. Neste caso poderiam estar afetados o trato espinotalâmico na medula espinhal, os axônios desses neurônios no bulbo, na ponte, no mesencéfalo e no lemnisco medial, o núcleo caudal lateral ventral no tálamo e seus axônios que se dirigem do tálamo para o córtex somestético através da cápsula interna, bem como os nervos e segmentos espinhais correspondentes (De Lahunta 1983).

A exposição do pênis observada em nossos experimentos foi relatada também por Roberts \& Seawright (1983). Esta manifestação foi descrita como um dos efeitos menos importantes das drogas agonistas $\mathrm{a}_{2}$-adrenérgicas (England \& Clarke 1996), grupo do qual, comprovadamente, o amitraz faz parte (Sellers et al. 1984, Roberts \& Argenzio 1986, Schaffer et al. 1990, Hovda \& McManus 1993, Duncan 1993, Pass \& Mogg 1995, Hugnet \& Cadoré 1995, Hugnet et al. 1996, Harkins et al. 1997, Queiroz-Neto et al. 1998). Esta alteração tem sido associada à utilização de drogas do grupo das fenotiazinas, que causam bloqueio dos receptores $\mathrm{a}_{1}$ (Speirs 1999). Acreditamos que a ação sobre esses dois receptores pode estar envolvida no aparecimento deste sintoma, uma vez que Reed \& Bayly (2000) afirmam que os efeitos periféricos dos agonistas $\mathrm{a}_{2}$-adrenérgicos são o resultado de uma combinação da ação sobre os receptores $a_{1}$ e $a_{2}$ adrenérgicos. Desta forma deve ser pesquisada uma possível lesão do nervo dorsal do pênis.

O sinal de compressão da cabeça observado no Eqüino 20 reflete alteração comportamental com origem nas estruturas que compõem o sistema límbico, principalmente nos lobos frontais e no tálamo rostral. (De Lahunta 1983)

Diante das alterações aqui discutidas, podemos inferir que a maior parte dos sinais clínicos observados neste estudo, devem se originar de lesões no tronco encefálico. Essa correlação entre os sinais clínicos e os locais afetados será efetivamente estabelecida quando da avaliação histológica e mapeamento das lesões no sistema nervoso.

A hipomotilidade/atonia intestinal foi o sinal digestivo mais consistente, sendo observada em 11 animais. Como consequiência ocorreu impactação do intestino grosso em 5 dos 6 animais em que essa alteração foi pesquisada; vários autores descreveram esta alteração. Foi sugerido que esses distúrbios ocorrem em conseqüência de alterações nos mecanismos de propulsão e retropulsão do intestino grosso (Sellers et al. 1982). Estes mecanismos são controlados por determinadas regiões da parede do intestino denominados de marcapasso, presentes no ceco, no cólon ventral direito e na flexura pélvica (Reed \& Bayly 2000). Lesões histológicas nestas áreas de marcapasso, bem como nos plexos submucoso e mioentérico da parede intestinal e nos plexos celíacomesentérico e mesentérico caudal devem ser pesquisadas. 0 edema dos lábios, que ás vezes acometia a região do focinho e das bochechas observado nos eqüinos 1, 2, 3, 18 e 19, foi também descrito por Roberts \& Seawright (1983) e Auer et al. (1984); em nosso ponto de vista este sintoma pode ter origem no posicionamento baixo da cabeça por longos períodos, o que pode dificultar a drenagem venosa desta região. A distensão abdominal observada em alguns animais também foi relatada por Auer et al. (1984) e Dearo \& Gandolfi (1995); 
esta alteração indica que órgaõs abdominais como o ceco, o cólon ou mesmo todo o intestino delgado estão distendidos (White, 1990). Os sinais de deitar e levantar freqüentemente, rolar no solo, olhar para o flanco, gemer e patear observados neste trabalho, bem como a postura de cão-sentado apresentada pelo Eqüino 19 em várias ocasiões e pelo Asinino, são sinais de dor abdominal (White, 1990) já relatados por vários autores (Roberts \& Seawright 1983, Auer et al. 1984, Dearo \& Gabdolfi 1995, Hugnet \& Cadoré 1995).

Taquicardia, sinal presente em todos os animais que mostraram sintomas da intoxicação, provavelmente seja conseqüente à dor abdominal e à desidratação determinadas pela a impactação do intestino grosso. Mucosas de coloração vermelha a vermelho-tijolo refletem congestão venosa e liberação de endotoxinas (White 1990), que certamente ocorreram nos animais utilizados neste trabalho. $\mathrm{O}$ aumento do tempo de preenchimento capilar traduz uma alteração da perfusão tecidual geralmente causada por desidratação (White 1990).

0 estridor observado em 5 dos 8 animais que adoeceram no experimento, também foi assinalado por Roberts \& Seawright (1983), que o atribuíram à baixa posição da cabeça. Além disso, a formação de edema nas narinas pode ter contribuído para a ocorrência deste sintoma. A taquipnéia, também descrita por Roberts \& Seawright, 1983; Auer et al (1984) e Dearo \& Gandolfi (1995) provavelmente deva-se à dor abdominal. Dispnéia e respiração abdominal verificadas em 4 animais podem estar relacionadas ao decúbito (White 1990). A secreção é, ao nosso ver, muito mais uma manifestação de disfagia, (Mayhew, 1989) do que um distúrbio respiratório propriamente dito. Isto pode ter ocorrido por um distúrbio nervoso (lesão no núcleo ambíguo) ou por irritação local, nos animais que receberam amitraz por via oral. Bradipnéia também foi reletada por Queiroz-Neto et al. (2000) que $\mathrm{a}$ atribuíram tal alteração à reduzida atividade do sistema nervoso central ou a uma menor necessidade de oxigênio nos animais sob efeito do amitraz. Outra possibilidade seria a broncodilatação determinada pelos agonistas $a_{2}$-adrenérgicos (Watney \& Hall 1988); neste caso a diminuição da frequiência respiratória seria uma resposta reflexa a alta capacidade de ventilação pulmonar, o que justificaria a afirmação de Jones \& Young (1991) de que todos os agonistas $a_{2}-$ adrenérgicos causam depressão respiratória.

A hipotermia, presente em 5 dos 8 animais que adoeceram também foi descrita. por Roberts \& Seawright (1983); esta alteração tem sido atribuída ao efeito agonista $a_{2}$ adrenérgicos (Poulsen Nautrup 1988). Por outro lado, altas doses de detomidina, um agonista $\mathrm{a}_{2}$-adrenérgico, provocou aparecimento tardio de hipertermia (Kamerling et al. 1988). Esta alteração foi observada na intoxicação por amitraz (Hugnet \& Cadoré 1995), bem como em nossos experimentos. Estes sintomas podem ter origem em lesões do hipotálamo, lesões no centro de perda de calor localizado na área hipotalâmica rostral e no centro de conservação de calor localizado nas áreas hipotalâmicas caudal e lateral causam hipertermia e hipotermia, respectivamente (De Lahunta 1983).

Diagnóstico diferencial
Ao nosso ver, nos casos naturais em que as manifestações digestivas como sinais de dor abdominal e impactação do intestino grosso vêm acompanhados de sinais nervosos como sonolência, diminuição de reflexos dos nervos cranianos e ataxia, o fechamento do diagnóstico não apresenta maiores dificuldades, uma vez que não conhecemos outra doença que provoque este quadro em eqüinos. Os casos naturais em que predominam as manifestações digestivas devem ser diferenciados de outras causas de impactação do intestino grosso. Esta enfermidade tem uma etiologia que envolve vários fatores como ingestão de alimentos grosseiros, defeitos de dentição que levam a mastigação inadequada e reduzida ingestão de água (White 1990). Por outro lado, quando existem sintomas nervosos evidentes como sonolência, ataxia e distúrbio de nervos cranianos, deve-se diferenciar a intoxicação por amitraz das doenças que afetam o sistema nervoso dos equiinos com acometimento importante do tronco encefálico, como por exemplo, a raiva, a encefalite por herpesvirus I e mais raramente, a encefalomielite equiina (quando sinais de envolvimento do tronco encefálico aparecem primeiro) (De Lahunta 1983, Mayhew 1989). A intoxicação também deve ser diferenciada da leucoencefalomalácia, da mieloencefalite por protozoário, ambas já descritas no Brasil. Para essas enfermidades, os aspectos epidemiológicos são bem distintos. Uma anamnese bem conduzida é de suma importância para a obtenção de dados sobre o uso de amitraz como carrapaticida nas $48 \mathrm{~h}$ anteriores.

\section{REFERÊNCIAS}

Auer D.E., Seawright A.A., Pollitt C.C. \& Williams G. 1984. .Illness in horses following spraying with amitraz. Aust. Vet. J. 61(8):257-259.

Aziz S.A. \& Knowles C.D. 1973. Inhibition of monoamineoxidase by the pesticide chlordimeform and related compounds. Nature 242:417-418. (Cit. Sakate et al. 1992)

Benezet H.J. \& Knowles C.O. 1976. Inhibition of rat brain monoamine oxidase by formamidines and related compounds. Neuropharmacology 15:369373.

Clark E.S. 1990. Intestinal motility, p. 36-48. In: White N.A. (ed.) The Equine Acute Abdomen. 1st ed. Lea \& Febiger, Pennsylvania. 434p.

Darvill F.M. 1985. Illness in horses following spraying with amitraz. Aust. Vet. J. 62(5): 176.

De Lahunta A. 1983. Veterinary Neuroanatomy and Clinical Neurology. 2nd ed. W. B. Saunders Company, London.

Dearo A.C.O. \& Gandolfi W. 1995. Síndrome cólica em eqüinos após uso tópico de amitraz (Triatox). Revta Bras. Med. Vet. 17(4):174-178.

Dirksen G., Gründer H. \& Stöber M. 1993. Rosenberger - Exame Clínico dos Bovinos. $3^{\mathrm{a}}$ ed. Guanabara Koogan, Rio de Janeiro.

Dobozy V.S. 1982. Mitabam Safety. DVM 13:54-55. (Cit. Schaffer et al. 1990)

Duncan K.L. 1993. Treatment of amitraz toxicosis. J. Am.Vet. Med. Assoc. 203(8): 1115.

England G.C.W. \& Clarke K.W. 1996. Alpha2-adrenoceptor agonists in the horse - a review. Brit. Vet. J. 152:641-656.

Florio J.C., Sakate M. \& Palermo Neto J. 1993. Effects of amitraz on motor function. Pharmacology and Toxicology 73:109-114.

Folz S.D., Kakuk T.J., Henke C.L., Rector D.L. \& Tesar F.B. 1984a. Clinical evaluation of amitraz as a treatment for canine demodicosis. Vet. Parasit. 16:335-341. (Cit. Sakate et al. 1992)

Folz S.D., Kakuk T.J., Henke C.L. Rector D.L.\& Tesar F.B. 1984b. Clinical 
evaluation of amitraz as a treatment for canine scabies. Mod.Vet. Pratic. 65:597-600. (Cit. Schaffer et al. 1990)

Goldberg M. \& Robertson D. 1983. Yohimbine: a pharmacological probe for studies of the alpha2-adrenoceptor. Pharmacol. Rev. 35:143-180. (Cit. Sakate et al. 1992)

Grossman M.R., Garvey M.S.\& Murphy M.J. 1993. Amitraz toxicosis associated with ingestion of an acaricide collar in dog. J. Am.Vet. Med. Assoc. 203:5557. (Cit. Hugnet et al. 1996)

Gunaratnam P., Wilkinson G.T \& Seawright A.A. 1983. A study of amitraz toxicity in cats. Aust. Vet. J. 60(9):278-279.

Harkins J.D., Queiroz-Neto A., Mundy G.D., West D. \& Tobin T. 1997. Development and characterization of na equine behavior chamber and the effects of amitraz and detomidine on spontaneous locomotor activity. J. Vet. Pharmacol. Therap. 20:396-401.

Harrison I.R., Kozlik A., McCarthy J.F., Palmer B.H., Wakerley S.B., Watkins T.I \& Weighton D.M. 1973. 1,3,5-Triazapenata-1,4-dienes: Chemical aspects of a new group of pesticides. Pestic. Sci. 4:901-910.

Hovda L. R. \& McManus A.C. 1993. Yohimbine for treatment of amitraz poisoning in dogs. Vet. Hum. Toxicol. 35(4):329.

Hugnet C. \& Cadoré J. L. 1995. Toxicologie de l'amitraze chez le cheval. Prat. Vét. Equine 27(3):139-141

Hugnet C., Buronfosse F., Pineau X., Cadoré J. L., Lorgue, G. \& Berny P. J. 1996. Toxicity and kinetics of amitraz in dogs. Am. J. Vet. Res. 57(10):1506 1510.

Jones R.D. 1990. Xylene/Amitraz: A Pharmacologic Review and Profile. Vet. Hum. Toxicol. 32(5):446-448.

Jones R.S. \& Young L.E. 1991. Medetomidine premedication in dogs and its reversal by atipamezole. Acta Veterinaria Scandinavica (Suppl.) 87:165-167. (Cit. England \& Clark 1996)

Kamerling S., Cravens W.M.T. \& Bagwell C.A. 1988a .Dose-related effects of detomidine on automatic effects of atipamezole in the horse. J. Autonomic Pharmacol. 8:241-249. (Cit. England \& Clarke 1996).

Kennel O., Prince, C. \& Garnier R. 1996. Four cases of amitraz poisoning in humans. Vet. Hum. Toxicol. 38(1):28-30.

Knowles C.O. \& Roulston W.J. 1973. J. Econ. Entomol. 66:1245. (Cit. Auer et al. 1984)

Mayhew I.G. 1989. Large Animal Neurology: A Handbook for Veterinary Clinicians. 1st ed. Lea \& Febiger, Philadelphia.

Muller G.H. 1983. Amitraz treatment of demodicosis. J. Am. Anim. Hosp. Assoc. 19:435 441. (Cit. Sakate et al. 1992)

Mutsaers C.W. \& Van Der Velden M.A. 1988. Twee gevallen van colon obstipatie bij pony's, vermoedelijk als gevolg van een behandeling met Takticâ. Tijdschr. Diergeneesk. 113(22): 1246-1248.

Pass M.A. \& Mogg T.D. 1995. Pharmacokinetics and metabolism of amitraz in ponies and sheep. J. Vet. Pharmacol. Therap. 18: 210-215.

Pass M.A. \& Seawright A.A. 1995. Effect of amitraz on contractions of the guinea pig ileum in vitro. Comp. Biochem. Physiol. Comp. Pharmacol. 73:419422. (Cit. Dearo \& Gandolfi 1995)

Poulsen Nautrup B. 1988. Clinical trial of the imino-imidazolidine derivative
STH 2130 as a sedative in comparison with acetylpromazine (Sedalin) and as a pre-anaesthetic in horses. Dr. Vet.Med Thesis, University of Berlin.

Pronckzuk J., Heus, L. \& Scaiola, G. 1986. Presentacion clinica colinergica de la intoxicacion aguta por amitraz. Toxicologia 1: 7-12. (Cit. Kennel et al. 1996)

Queiroz-Neto A., Zamur G., Gonçalves S. C., Carregaro A. B., Mataqueiro M. I., Harkins J.D. \& Tobin, T. 1998. Characterization of the antinociceptive and sedative effect of amitraz in horses. J. Vet. Pharmacol. Therap. 21:4000-405.

Queiroz-Neto A., Carregaro G.Z., Zamur G., Harkins J. D. \& Tobin T. 2000. Effect of amitraz and xylazine on some physiological variables of horses. Arq. Bras. Med. Vet. Zootec. 52(1):27-32.

Radostits O.M., Gay C.C., Blood D.C. \& Hinchcliff K.W. 2002. Clínica Veterinária: Um Tratado de Doenças dos Bovinos, Ovinos, Suínos, Caprinos e Equiinos. $9^{\mathrm{a}}$ ed. Guanabara Koogan, Rio de Janeiro.

Reed S.M. \& Bayly W.M. 2000. Medicina Interna Eqüina. $1^{\text {a }}$ ed. Guanabara Koogan, Rio de Janeiro.

Roberts M.C. \& Argenzio A. 1986. Effects of amitraz, several opiate derivatives and anticholinergic agents on intestinal transit in ponies. Equine Vet. J. 18(4):256-260.

Roberts M.C. \& Seawright A.A. 1979. Amitraz induced large intestinal impaction in the horse. Aust. Vet. J. 55:553-554.

Roberts M.C. \& Seawright A.A. 1983. Experimental studies of drug-induced impaction colic in the horse. Equine Vet. J. 15(3):222-228.

Roy-Smith F. 1975. Insecticide and Fungicide Conf., Brighton. (Cit. Auer et al. 1984).

Sakate M., Florio J.C., Palermo Neto J. 1992. Efeitos tóxicos do praguicida amitraz: uma revisão. Comun. Cient., Fac. Med. Vet. Zootec. Univ. S. Paulo, 16(1/2):45-51.

Schaffer D.D., Hsu W.H \& Hopper D.L. 1990. The effects of yohimbine and four other antagonists on amitraz-induced depression of shuttle avoidance responses in dogs. Toxicol. Appl. Pharmacol. 104:543-547.

Seawright A.A. Observações não-publicadas. (Cit. Auer et al. 1984)

Sellers A.F., Lowe J.E., Drost J.C., Rendano V.T., Georgi J.R.\& Roberts M.C. 1982. Retropulsion-propulsion in equine large colon. Am. J. Vet. Res. 43(3):390-396.

Sellers A.F., Lowe J.E. \& Cummings J.F. 1984. Trials of serotonine, substance P and $\mathrm{a}_{2}$-adrenergic receptor effects on the equine large colon. Cornell Vet. 75:319-323.

Speirs V.C. 1999. Exame Clínico dos Eqüinos. $1^{\text {a }}$ ed. Artmed, Porto Alegre.

Squires R.L. 1972. Multiple forms of monoamine oxidase in intact mitochondria as characterized by selective inhibitors and thermostabily: a comparison of eight mamalian species. Adv. Biochem. Psychopharmacol. 5:355-370. (Cit. Sakate et al, 1992)

Watney G.C.G. \& Hall L.W. 1988. Effects of xylazine and acepromazine on broncomotor tone of anaesthetized ponies. Equine Vet. J. 20:185-188. (Cit. Queiroz-Neto et al. 2000)

White N.A. 1990. Examination and diagnosis of the acute abdômen, p. 102142. In: White N.A. (ed.) Equine Acute Abdomen. 1st ed. Lea \& Febiger, Pennsylvania. 434p. 